\title{
Refractory anaemia terminating in a combined lymphoproliferative and myeloproliferative disorder
}

\author{
L CAMBA, MV JOYNER
}

From the Royal Devon and Exeter Hospital (Wonford), Exeter, Devon

SUMMARY We report a case of non-sideroblastic refractory anaemia which evolved to a double lymphomyeloproliferative disorder. At presentation, bone marrow appearances and peripheral blood pancytopenia without myelomonocytosis were consistent with a diagnosis of nonsideroblastic refractory anaemia. Subsequently, the patient developed pronounced myelomonocytosis and lymphocytosis with prolymphocytes. Light and transmission electron microscopy as well as surface marker studies were compatible with a diagnosis of prolymphocytic transformation of chronic lymphocytic leukaemia/prolymphocytic leukaemia associated with myelomonocytic leukaemia. The pathogenesis of such double lympho-myeloproliferative disorders is discussed in the light of the evidence for common lymphoid and myeloid progenitor cells and some recent advances in the immunology of the myelodysplastic syndromes.

Non-sideroblastic refractory anaemia is a myelodysplastic syndrome characterised by peripheral blood cytopenia involving one or more cell lines, normal or increased bone marrow cellularity with fewer than $5 \%$ blasts, and absence of ringed sideroblasts. ${ }^{1}$ Patients are middle aged or elderly; median survival is about $36-40$ months, ${ }^{2}$ although some patients have survived more than 20 years. $^{3}$ Death supervenes after infective or haemorrhagic complications ${ }^{2}$ or as a consequence of transfusion induced haemosiderosis. ${ }^{4}$ Acute non-lymphocytic leukaemia and myelomonocytic leukaemia develop in about $30 \%$ of the patients. ${ }^{23}$

The simultaneous occurrence of a lymphoproliferative and myeloproliferative disorder in the same patient is well recognised. ${ }^{5}$ However, the association of myelomonocytic leukaemia with a prolymphocytic transformation of chronic lymphocytic leukaemia/prolymphocytic leukaemia, as well as the evolution of non-sideroblastic refractory anaemia to a mixed lymphomyeloproliferative dyscrasia, have not, we believe, been described previously.

\section{Case report}

An 80 year old woman presented in July 1982 with a six month history of fatigue, dyspnoea, epistaxis, and easy bruising. In May 1982 she had developed

Accepted for publication 21 November 1984 congestive cardiac failure and had been found to be anaemic. Treatment with iron resulted in no improvement in her anaemia. Two weeks before admission an episode of gout was treated with phenylbutazone. Her medical history contained nothing of note apart from chronic bronchitis. There was no history of chemotherapy or radiotherapy or excessive exposure to radiological investigations.

Physical examination on admission revealed a pale but fit woman with ecchymoses on both legs and abdomen, a soft systolic murmur at the apex, diffuse rhonchi over both lungs, and mild bilateral ankle oedema. There was no lymphadenopathy; liver and spleen were not enlarged. Results of biochemical investigations on admission were as follows: haemoglobin concentration $7 \cdot 7 \mathrm{~g} / \mathrm{dl}$, mean cell volume $92 \mathrm{fl}$, reticulocytes $<1 \%$, white cell count 4.9 $\times 10^{9} / 1$ (differential count: neutrophils $27 \%$, lymphocytes $71 \%$, eosinophils $2 \%$ ), platelet count $97 \times$ $10^{9} / 1$. Red cell folate and a serum biochemical survey were normal except for a creatinine concentration of $181 \mu \mathrm{mol} / 1$ (normal 50-120). A chest radiograph showed an increased heart size and degenerative changes in the thoracic spine. A sternal bone marrow aspirate (Fig. 1) exhibited the following: a considerably increased cellularity with moderate dyserythropoiesis, including prominent megaloblastoid changes; granulopoietic precursors were hypogranular and dysplastic with frequent monocytoid forms; megakaryopoiesis was reduced; sideroblasts were present in normal numbers; ringed forms were 


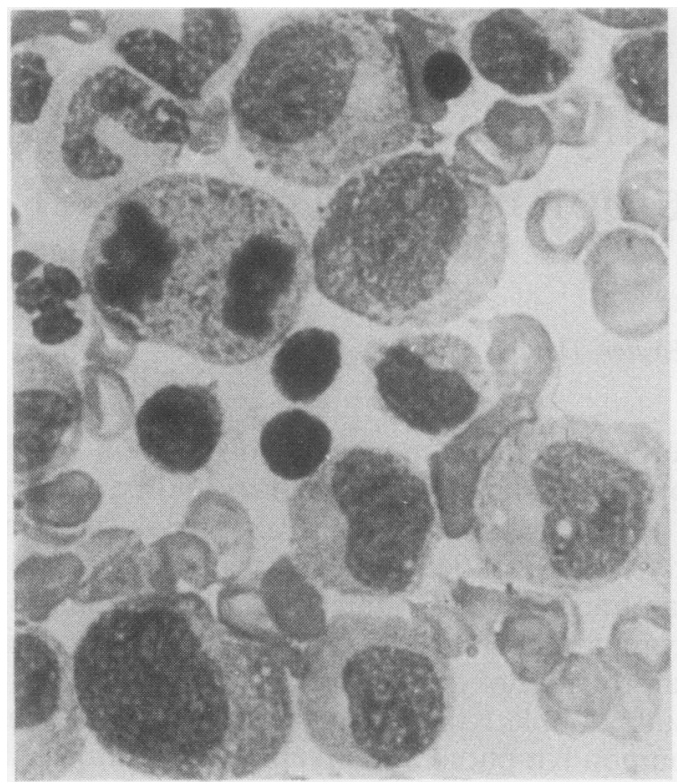

Fig. 1 Bone marrow aspirate at presentation showing dysplasia of the myelo-erythroid series.

absent. Non-sideroblastic refractory anaemia with hypercellular bone marrow was diagnosed. The patient was given four units of concentrated red blood cells and sent home. Clinically, she remained

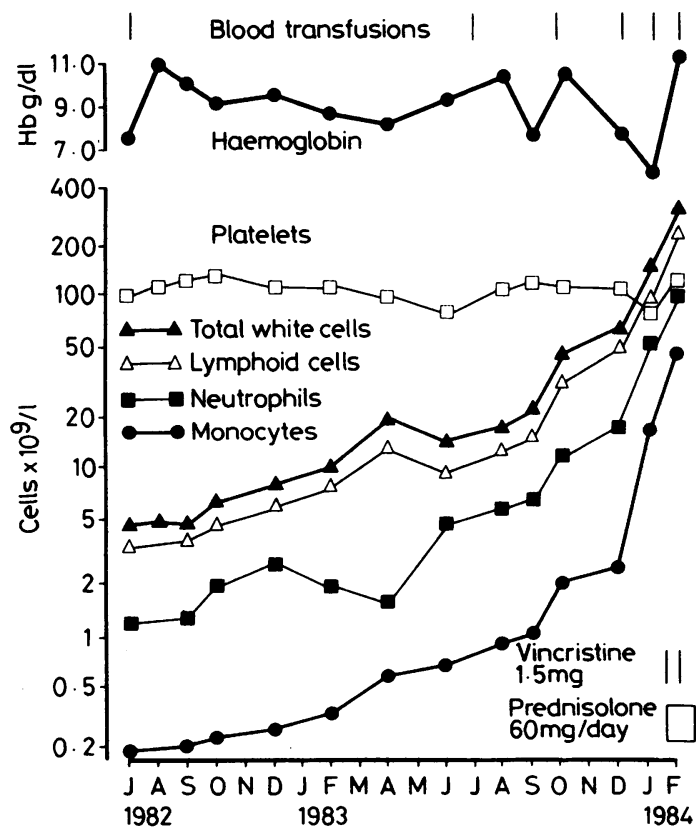

Fig. 2 Haematological course since presentation.

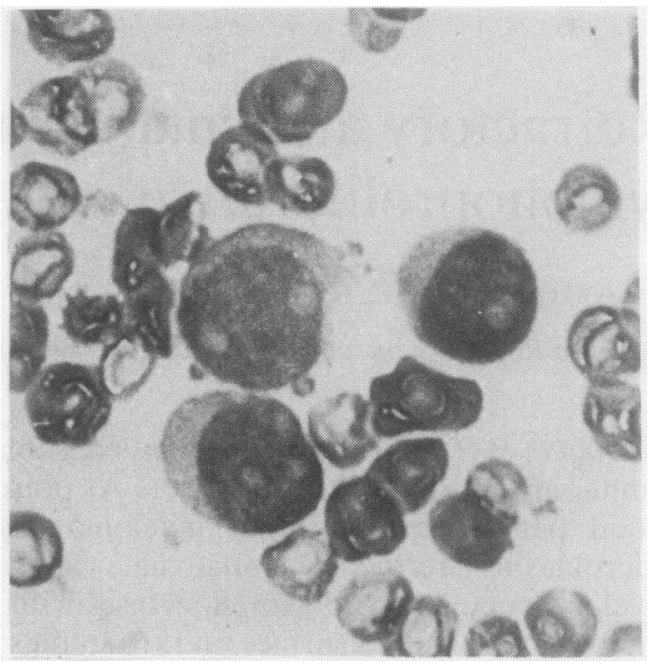

Fig. 3 Peripheral blood prolymphocytes with prominent nucleoli.

well until December 1983, when she received blood transfusions on four occasions.

Throughout this period the spleen enlarged slowly, and in December 1983 it could be felt $6 \mathrm{~cm}$ below the costal margin. At no time was there palpable lymphadenopathy. The haematological course over the same period was characterised by a progressive increase in the white cell count (Fig. 2) and the appearance of prolymphocytes in the peripheral blood (Fig. 3). A leucocyte alkaline phosphatase score was $0 \%, 2 \%$, and $2 \%$ on three different occasions. Urine lysozyme was 4.9 units in December 1983 (normal <1). Subsequent bone marrow aspirates, apart from showing moderate lymphocyte infiltration and some prolymphocytes and monocytes, remained substantially unaltered (Table). In January 1984 her health deteriorated rapidly, and this coincided with a rapid increase in the white cell

Bone marrow differential counts

\begin{tabular}{|c|c|c|c|c|}
\hline & July 1982 & May 1983 & July 1983 & Dec 1983 \\
\hline Neutrophfls & 10 & 4 & 10 & 9 \\
\hline Band forms & 8 & 3 & 6 & 11 \\
\hline Metamyelocytes & 10 & 15 & 12 & 14 \\
\hline Myelocytes & 30 & 19 & 11 & 13 \\
\hline Promyelocytes & 5 & 8 & 7 & 10 \\
\hline Myeloblasts & 1 & 2 & 1 & 4 \\
\hline Monocytes & 8 & 4 & 3 & 5 \\
\hline Lymphocytes & 7 & 26 & 23 & 20 \\
\hline Prolymphocytes & - & 5 & 4 & 5 \\
\hline \multicolumn{5}{|c|}{ Normoblasts } \\
\hline Orthochromatic & 10 & 6 & 9 & 4 \\
\hline Polychromatic & 6 & 7 & 10 & 2 \\
\hline Basophilic & 4 & 1 & 3 & 2 \\
\hline \multirow{2}{*}{$\begin{array}{l}\text { Pronormoblasts } \\
\text { Myeloid:erythroid } \\
\text { ratio }\end{array}$} & - & - & 1 & - \\
\hline & 3·3:1 & 3.6:1 & $2: 1$ & 7·9:1 \\
\hline
\end{tabular}




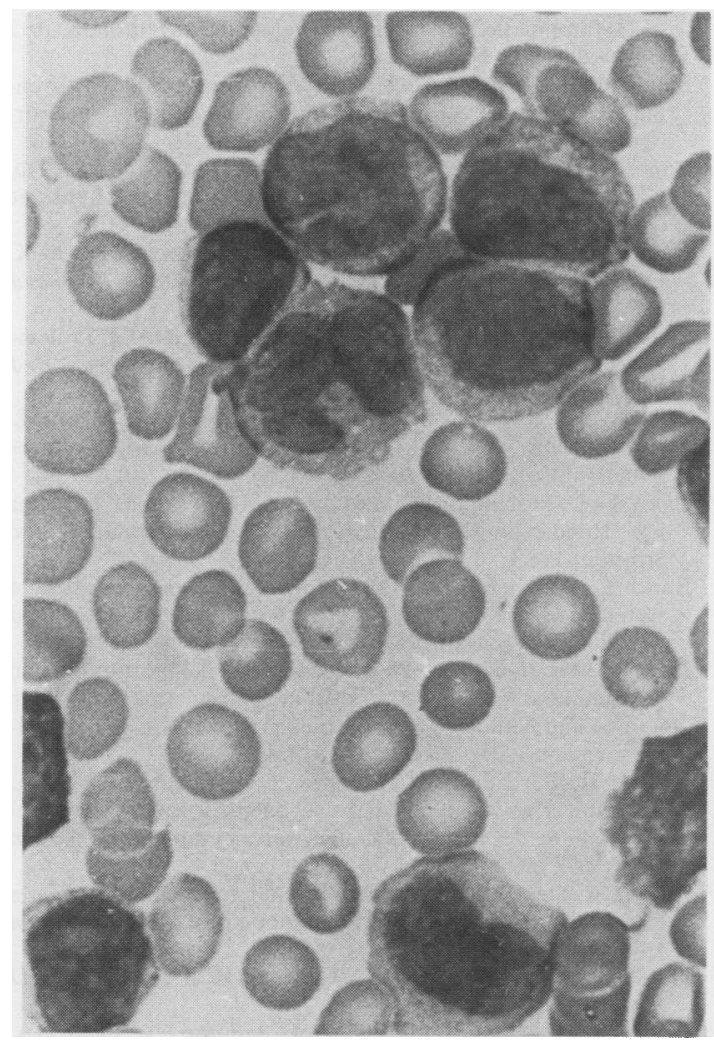

Fig. 4 Peripheral blood film showing granulocytic precursors, monocytes, and prolymphocytes.

count (Figs. 2 and 4). Surface markers studies of Ficoll enriched mononuclear cells showed: sürface marker immunoglobulin $66 \%$; $\kappa$-chains $6 \%$; $\lambda$-chains $75 \%$; mouse rosettes $3 \%$; FMC7 monoclonal antibody reactive cells $49 \%$. Transmission electron microscopy confirmed the presence of typical prolymphocytes.

Chemotherapy with vincristine and prednisolone was started on 1 February 1984 , but the white cell count continued to rise and reached $370 \times 10^{9} / 1$ on 20 February. The patient suffered a cerebrovascular accident and died the following day. Postmortem examination was not performed.

\section{Discussion}

The initial diagnosis of non-sideroblastic refractory anaemia in our patient was based on peripheral blood cytopenia, hypercellular bone marrow, and absence of ringed sideroblasts. The subsequent lymphoproliferative disorder showed the morphological features of prolymphocytic transformation of chronic lymphocytic leukaemia as described by
Enno et al ${ }^{6}$ although some clinical, morphological, and immunological features were in common with features of prolymphocytic leukaemia. The lack of lymphadenopathy and the absence of a chronic phase of chronic lymphocytic leukaemia fits with a diagnosis of prolymphocytic leukaemia, ${ }^{7}$ while the progressive increase in prolymphocytes in the peripheral blood is suggestive of prolymphocytic transformation of chronic lymphocytic leukaemia. ${ }^{6}$ Prolymphocytes from prolymphocytic leukaemia and prolymphocytic transformation of chronic lymphocytic leukaemia are morphologically identical both on light microscopy and on transmission electron microscopy. ${ }^{68}$

The affinity for FMC7 monoclonal antibody is compatible with a diagnosis of both prolymphocytic transformation of chronic lymphocytic leukaemia and prolymphocytic leukaemia. ${ }^{9}$ The low proportion of mouse rosettes is a typical finding of prolymphocytic leukaemia, ${ }^{10}$ although a reduction of this marker may parallel the increase of prolymphocyte count in some cases of prolymphocytic transformation of chronic lymphocytic leukaemia (D Catovsky; personal communication). The lymphoproliferative disorder in this patient showed clinical, morphological, and immunological features of both prolymphocytic leukaemia and prolymphocytic transformation of chronic lymphocytic leukaemia. It may indeed represent a transitional form between $B$ cell chronic lymphocytic leukaemia and B cell prolymphocytic leukaemia as previously suggested. ${ }^{9}$ It is possible that in the absence of the pre-existing refractory anaemia the lymphoproliferative disorder would have manifested itself at a later stage with a full blown picture of prolymphocytic leukaemia.

Pronounced monocytosis and neutrophilia are often encountered in haematological and nonhaematological malignancies." The leucocyte alkaline phosphatase score is usually normal in myelomonocytosis associated with neoplastic disorders, ${ }^{12}$ and is generally low in myelodysplastic syndrome and myelomonocytic leukaemia, ${ }^{13}$ as was the case in our patient. Furthermore, a range of transitional forms from myelodysplastic syndrome to chronic, subacute, and acute myelomonocytic leukaemia can be found in the same patient. ${ }^{14}$ Persistently low blast counts in our patient's bone marrow rules out acute myelomonocytic leukaemia.

The pathogenesis of such mixed lymphomyeloproliferative disorders is obscure. While their simultaneous occurrence may be fortuitous, the evidence for the existence of a pluripotent stem cell common to both lymphoid and myeloid progenies suggests the possibility of a monoclonal origin. ${ }^{15}$ The assumption of a monoclonal derivation would require the presence of common cell markers, such 
as identical chromosome abnormalities or identical glucose-6-phosphate dehydrogenase isoenzymes in both cell lines. Prchal et al ${ }^{16}$ described a case of myelodysplastic syndrome with no associated lymphoproliferative disorder in which both lymphoid and myeloid cell populations possessed identical glucose-6-phosphate dehydrogenase isoenzymes. The lymphoid cells in this case, although originated from a neoplastic cell progenitor, did not express their neoplastic potential in a disorderly proliferation. It is possible that a further tumorigen stimulus is needed for the onset of the second malignancy and the role of lymphohaematopoietic autostimulatory growth factors cannot be excluded. ${ }^{17}$ It has been suggested that immunological defects secondary to the lymphoproliferative disorder might predispose to the myeloid malignancy. ${ }^{5}$ In our case the clinical and haematological findings of myelodysplastic syndrome had preceded the onset of the lymphoproliferative disorder. An impaired immune surveillance is well documented in elderly subjects ${ }^{18}$ while decreased natural killer cell activity has recently been shown in patients with myelodysplastic syndromes. ${ }^{19}$ A complex immunological defect might therefore have triggered the second malignancy in our case.

We thank Dr PP Anthony and Dr D Catovsky for useful discussion and $\mathrm{Dr}$ MF Greaves for the immunological studies. We also thank Mr I Jury for the electron micrographs and Mrs K Sampson for the preparation of the manuscript.

\section{References}

' Bennett JM, Gatovsky D, Daniel MT et al. Proposal for the classification of the myelodysplastic syndromes. Br J Haematol 1982;51:189-99.

${ }^{2}$ Rosenthal DS, Maloney WC. Refractory dysmyelopoietic anaemia and leukaemia. Blood 1984;63:314-8.

${ }^{3}$ Geschke W, Beutler E. Refractory sideroblastic and nonsideroblastic anaemia. A review of 27 cases. West $\mathrm{J} \mathrm{Med}$ 1977; 127:85-92.

${ }^{4}$ Cazzola M, Barosi G, Berzuini C, et al. Quantitative evaluation of erythropoietic activity in dysmyelopoietic syndromes. $\mathrm{Br} \mathrm{J}$ Haematol 1982; 50:55-62.

${ }^{5}$ Manoharan A, Catovsky D, Clein P et al. Simultaneous or spontaneous occurrence of lympho-and myeloproliferative disorders: a report of four cases. Br J Haematol 1981;48:111-6.

- Enno A, Catovsky D, O'Brien M, Cherch M, Kumaran TO, Galton DAG. "Prolymphocytoid" transformation of chronic lymphocytic leukaemia. Br J Haematol 1979;41:9-18.

' Galton DAG, Goldman JM, Wiltshaw E, Catovsky D, Henry K, Goldberg GJ. Prolymphocytic leukaemia. Br J Haematol 1974;27:7.

${ }^{8}$ Costello C, Catovsky D, O'Brien M, Galton DAG. Prolymphocytic leukaemia: an ultra structural study of 22 cases. Br J Haematol 1980;44:389-94.

' Catovsky D, Cherchi M, Brooks D, Bradley J, Zola H. Heterogeneity of B cell leukaemias demonstrated by monoclonal antibody FMC7. Blood 1981;58:406-8.

${ }^{10}$ Catovsky D. Prolymphocytic and hairy cell leukaemias. In: Gunz FW, Henderson ES, eds. Leukaemia. New York: Grune and Stratton, 1983.

"Bunch C, Weatherall DJ. The haematological manifestation of systemic disease. In: Hardisty RM, Weatherall DJ, eds. Blood and its disorders, Oxford: Blackwell, 1982.

${ }^{12}$ Hayhoe FGJ, Quaglino D. Cytochemical demonstration and measurement of leucocyte alkaline phosphatase activity in normal and pathological states by a modified Azo-Dye coupling technique. Br J Haematol 1958;4:375-89.

${ }^{13}$ Zittoun R, Bernadou A, Zittoun J, Cadiou M. Et Degos L. Leucémie myelo-monocytaire subaiguë. Etude cyto- et biochimique des lignées granulocythires et monocytaires. Sem Hop Paris 1972;48:1965-70.

${ }^{14}$ Zittoun R. Subacute and chronic myelomonocytic leukaemia: a distinct haematological entity (annotation). Br J Haematol 1976;32:1-7.

${ }^{15}$ Quesenberry P, Levitt L. Hematopoietic stem cells. $N$ Engl J Med 1979;301:755-60.

${ }^{16}$ Prchal JT, Throckmorton DW, Carrol EJ, Fuson EW, Qams RA Prchal JF. A common progenitor for human myeloid and lymphoid cells. Nature 1978;274:590-1.

"Schrader JW. Role of a single haemopoietic growth factor in multiple proliferative disorders of haemopoietic and related cells. Lancet 1984;ii:133-6.

${ }^{18}$ Roberts-Thompson IC, Youngchaiyud U, Whittingham S, Mackay IR. Ageing, immune response and mortality. Lancet 1974;ii:368-70.

${ }^{14}$ Kerndrup G, Meyer K, Ellegaard J, Hokland P. Natural killer (NK) - cell activity and antibody-dependent cellular cytotoxicity (ADCC) in primary preleukaemic syndrome. Leukaemia Res 1984;8:239-47.

Requests for reprints to: Dr MV Joyner, Consultant Haematologist, Royal Devon and Exeter Hospital (Wonford), Barrack Road, Exeter, EX2 5DW, England. 